\title{
Numerical simulations of competition in quantities $^{\text {is }}$
}

\author{
Devon Gorry*, John Gilbert \\ Department of Economics \& Finance, Utah State University, United States
}

\section{A R T I C L E I N F O}

\section{Article history:}

Received 24 March 2014

Received in revised form 6 October 2014

Accepted 19 January 2015

Available online 24 February 2015

\section{JEL classification:}

A22

C63

D43

Keywords:

Excel

Numerical model

Competition in quantities

\begin{abstract}
A B S T R A C T
We present a series of numerical simulation models built in Excel that can be used to explore the properties of various models of strategic competition in quantities and their economic implications. The resources incorporate both tabular and graphical data presentation formats and are built in such a way that they provide instant or 'live' feedback on the consequences of changes in the economic system. We discuss the theory behind the models, how they can be implemented as numerical simulations in Excel, and ways in which the simulations can be used to enhance student understanding of the material.
\end{abstract}

(c) 2015 Elsevier Ltd. All rights reserved.

\section{Introduction}

Models of strategic competition in quantities are a mainstay of the undergraduate curriculum at multiple levels. The Cournot model of oligopoly is frequently taught in both introductory and intermediate microeconomics, and its various extensions form a core component of most courses in industrial organization. Moreover, models of competition in quantities are also commonly used in the international trade classroom when covering 'new' trade theory models of the reciprocal dumping variety. The models provide important insights into core concepts from game theory and into the implications of variations in market structure for economic outcomes. Hence, it is important that students develop a solid understanding of the properties of these models.

\footnotetext{
John Gilbert would like to thank the Abe Fellowship program for financial support during work on this project.

* Corresponding author at: 3565 Old Main Hill, Logan, UT 84322-3565, United States. Tel.: +1 4357979098.

E-mail address: devon.gorry@usu.edu (D. Gorry).
} 
There are a number of ways to teach models of strategic competition in quantities like the Cournot model. At the principles level a graphical approach is likely to be adopted, while in intermediate and senior-level industrial organization classes, simple models of competition in quantities are often used to introduce more general concepts from game theory and are typically solved algebraically for simple functional forms. A useful analog to these approaches is the use of numerical examples, which are a good mechanism for developing economic intuition. Numerical simulation makes abstract results more compelling for students, allows faster and more general demonstration of model properties, and can help connect models based on a common foundation. There are a wide range of examples in the literature, including models from microeconomics principles (Mixon and Tohamy, 2000), international trade (Gilbert and Oladi, 2011), macroeconomics (Findley, 2014) and financial economics (Guo and Gilbert, 2014).

While there are many platforms on which numerical simulations can be built, Excel has a number of advantages for pedagogical purposes. ${ }^{1}$ It allows for both tabular and graphical presentations of information, can be used to solve quite complex problems, and is widely available on many computer platforms. It is a also a program with which most students are already familiar, and it is widely used outside of the classroom.

In this paper we describe a series of numerical simulation models built in Excel that can be used to support instruction on models of strategic competition in quantities. As in Guo and Gilbert (2014), the models are built in such a way that they respond instantly to changes, have a consistent presentation across various extensions, and gradually build complexity onto a common foundation. ${ }^{2}$ The paper is organized as follows. In the next section we set out the structure of the basic model and its solution, followed by a review of the geometry of the problem. We then turn to the question of how to implement the model as a numerical simulation in Excel. Next, we discuss how the resources we have built can be obtained and used, and we provide details on various extensions. Throughout we provide examples of exercises that can be used to explore the implications of differences in market structure for various economic variables of interest. We conclude with a few notes on how the approach we have taken in this paper could be extended to other topics.

\section{The basic Cournot duopoly}

We begin by sketching the basic Cournot duopoly model and its solution. We follow a standard, textbook approach and assume: (1) there are two firms (no entry); (2) firms have constant marginal and average costs, denoted $c_{i}$; (3) the firms are producing a homogeneous product; (4) the overall market demand function is linear, with the inverse demand being specified as $P(Q)=a-b Q$ where $a$, $b>0$ and $a>c_{i}$; and (5) the firms must choose their outputs simultaneously. ${ }^{3}$

The Cournot output represents a Nash equilibrium in a game where firms simultaneously choose output. Thus, the equilibrium is a list of price and output levels for each firm such that neither firm can increase their profits by changing their output given that the other firm does not change their output. Formally, the Cournot-Nash equilibrium is a triplet $\left\{p^{c}, q_{1}^{c}, q_{2}^{c}\right\}$ such that:

- Given $q_{2}=q_{2}^{c} ; q_{1}^{c}$ solves $\max _{q_{1}} \pi_{1}\left(q_{1}, q_{2}^{c}\right)$

- Given $q_{1}=q_{1}^{c} ; q_{2}^{c}$ solves $\max _{q_{2}} \pi_{2}\left(q_{1}^{c}, q_{2}\right)$

- $p^{c}=a-b\left(q_{1}^{c}+q_{2}^{c}\right)$

We begin by solving firm 1's maximization problem, whereby firm 1 chooses it's profit maximizing quantity and takes firm 2's quantity as given. This yields firm 1's best response function, $R_{1}\left(q_{2}^{c}\right)$.

\footnotetext{
${ }^{1}$ Excel is useful in other contexts too. Wight (1999) discusses some general benefits of using spreadsheets beyond numerical simulation, while Briand and Hill (2013) consider the use of Excel for econometrics.

2 While we present the models as a progression from relatively simple models to more complex ones, instructors may use the resources in the reverse order if they prefer. The model of monopolistic competition is the most general, and the others can be classed as special cases derived by adding more restrictive assumptions.

${ }^{3}$ A more complete treatment of the model, and those that follow, can be found in typical industrial organization texts, such as Carlton and Perloff (2005).
} 


$$
\max _{q_{1}}\left(a-b\left(q_{1}+q_{2}^{c}\right)\right) q_{1}-c_{1} q_{1}
$$

The first order condition for a maximum is: ${ }^{4}$

$$
a-2 b q_{1}-b q_{2}^{c}-c_{1}=0
$$

and the explicit best response function is:

$$
R_{1}\left(q_{2}^{c}\right)=\frac{a-c_{1}}{2 b}-\frac{1}{2} q_{2}^{c}
$$

Using symmetry, firm 2's maximization will yield a similar best response function, $R_{2}\left(q_{1}^{c}\right)$.

$$
R_{2}\left(q_{1}^{c}\right)=\frac{a-c_{2}}{2 b}-\frac{1}{2} q_{1}^{c}
$$

Equilibrium occurs at the intersection of these two best response functions. By substituting firm 2's best response function into firm 1 's, we solve for $q_{1}^{c}$ :

$$
q_{1}^{c}=\frac{a-2 c_{1}+c_{2}}{3 b}
$$

and similarly for $q_{2}^{c}$,

$$
q_{2}^{c}=\frac{a-2 c_{2}+c_{1}}{3 b}
$$

Market quantity is given by $Q^{c}=q_{1}^{c}+q_{2}^{c}$, while the price is $p^{c}=a-b Q^{c}$. We can then substitute back for the firm's profits, consumer surplus, or any other economic variable of interest.

\section{The geometry of the solution}

The solution to the model can be illustrated in several ways. In Fig. 1, we show the profit maximizing output choice of firm 1 for any given level of output of firm 2 . The line labeled $D$ is the market demand curve. Subtracting the quantity produced by firm $2\left(q_{2}\right)$ from the market demand curve yields the residual demand curve for firm 1, labeled $R D_{1}$. The line labeled $c_{1}$ is firm 1's marginal (and average) cost. The firm maximizes profit by producing the quantity where the marginal revenue arising from the residual demand curve (labeled $M R_{1}$ ) is equal to the marginal cost, at point $a$. Drawing a vertical line up to the residual demand curve (at $b$ ) yields the market price. Since the distance $b d$ is equal to $q_{2}$, the market clears. A similar diagram can be constructed for firm 2 .

The equilibrium outcome for both firms is described in Fig. 2 . The best response functions describe the profit maximizing output choices of each firm as a function of the output choices of the rival. The best response of firm 1 is labeled $R_{1}$, while that of firm 2 is labeled $R_{2}$. The Nash equilibrium is where the two best responses coincide, i.e., point $a$.

The best response functions have the property that profit is maximized for firm 1 at point $b$, and for firm 2 at point $c$. These are the monopoly levels of output. Profit is minimized for firm 1 at point $d$, and for firm 2 at point $e$, which correspond to where price equals marginal cost, or the competitive level of output.

While the Cournot model is static in nature, the best response curves can also be used to show that if we start at a disequilibrium point, the adjustment process will converge to the Nash Equilibrium using best response dynamics (as long as firm 2's best response is steeper than firm 1's in the two good case). Starting from any point, one can imagine firms responding sequentially to the other firm's output based on the best response curves which will move the firms towards the equilibrium point. These dynamics can help students imagine an adjustment process and also understand the stability of the equilibrium. ${ }^{5}$

\footnotetext{
${ }^{4}$ It is easy to see that the second-order condition is also satisfied.

${ }^{5}$ See Durlauf and Blume (2008) for a discussion on stability and Cabral (2000) for a dynamic interpretation.
} 


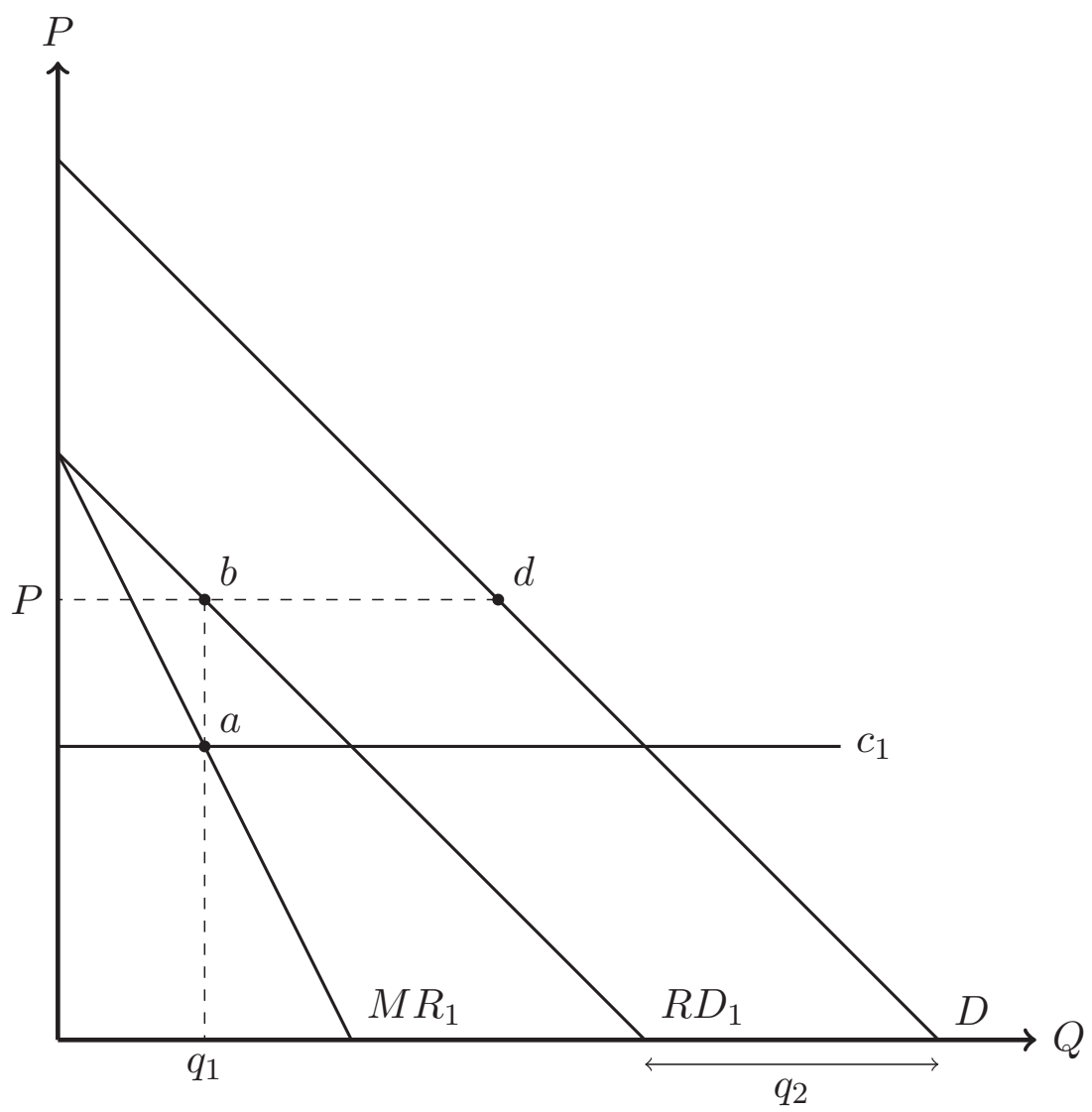

Fig. 1. The Decision of Firm 1

Conceptually, we can also envisage the best response functions in terms of two sets of concave isoprofit curves, with higher profits to each firm the lower the rival's output. The loci of the peaks of the isoprofits are the best response functions. Hence, at the Cournot-Nash equilibrium, the isoprofit curves are orthogonal. Since they are concave, it must be possible to find a Pareto improvement over the Nash equilibrium. That is, if both firms could agree to reduce output, they could both enjoy higher profits.

The solution to the joint profit maximization problem in fact lies at any point along the dotted line between $c$ and $b$, which is the locus of tangencies of the isoprofits of each firm. ${ }^{6}$ The point labeled $f$ is one such solution, with each firm producing exactly half the monopoly level of output. Point $g$ represents the equilibrium that would be obtained if the firms move sequentially (with firm 1 deciding on its output level first). We discuss this case further below.

\section{Building an Excel version}

There are a number of ways to build a simulation model in Excel. In many cases, the SOLVER add-in is used. This feature can solve optimization problems directly, but requires that the add-in be correctly installed and set up. It also requires that the optimization routine be launched, either manually or via a

\footnotetext{
${ }^{6}$ Assuming symmetric marginal costs. If marginal costs differ, the joint profit maximizing solution is at the end point of the best response function of the lower cost firm.
} 


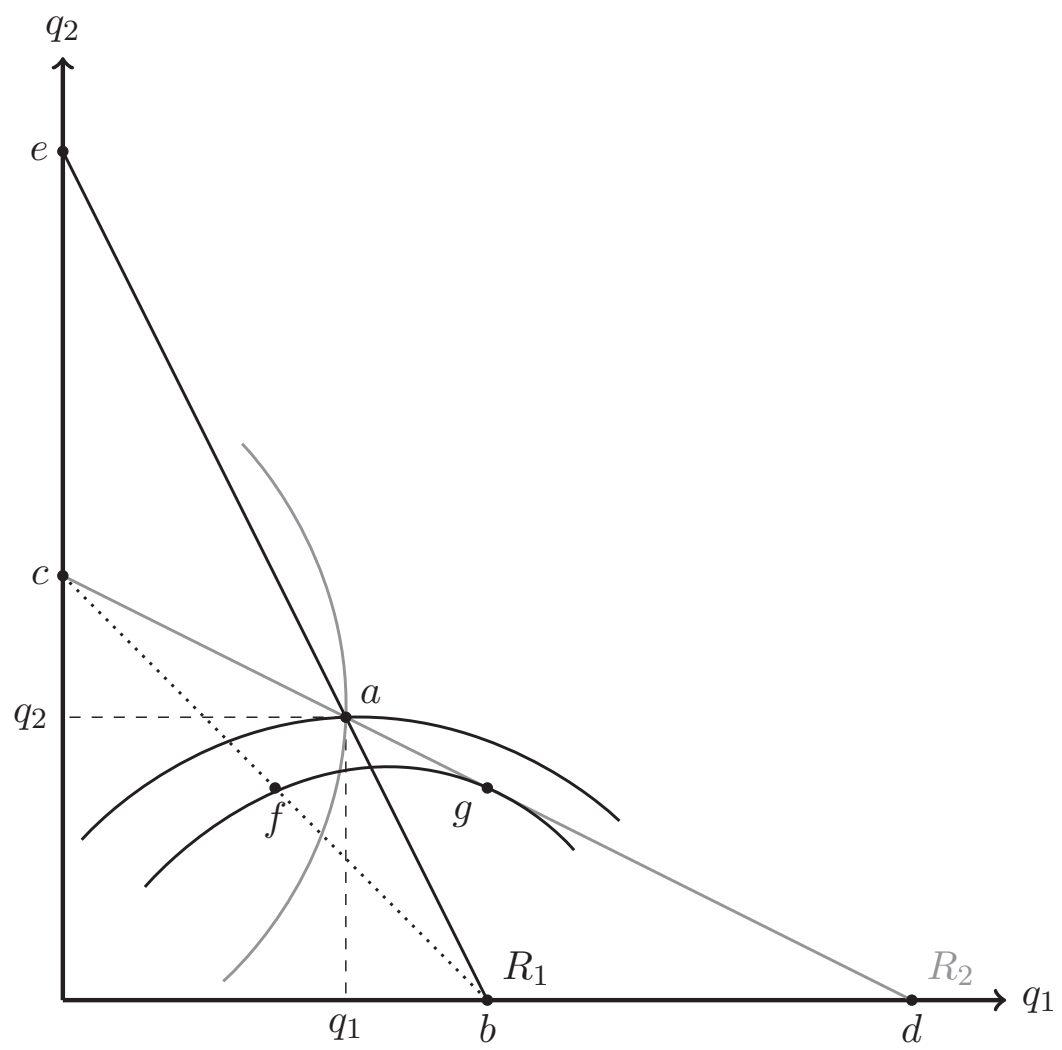

Fig. 2. Equilibrium outcomes.

macro, before a change can be observed. Hence, it adds a degree of complexity to the model-building and is best used when the problem involves significant nonlinearities and/or when obtaining closed form solutions is difficult.

In the case at hand, the use of linear demand and cost functions makes solving the problem for a closed form solution relatively simple, so we can implement the solution directly in the Excel sheets' cells. This has the advantage of avoiding potential difficulties with SOLVER and also makes the entire model 'live' in the sense that it responds instantly to any changes in parameters.

The process is quite straightforward. We begin by designating cells to hold values for exogenous parameters. In Fig. 3 these are cells D5, D6, D10 and D18. Next we allocate cells to contain the values of the endogenous variables, blocking them into logical groups (cells D11 through D14, D19 through D22 and D26 through D29). For consistency across the various sheets, we have adopted the coloring convention that white cells can be changed and those in gray are derived from the model.

To fill in the endogenous variables, we enter the solutions as formulas involving the exogenous variable cells. We begin with the solutions for $q_{1}^{c}$ and $q_{2}^{c}$. In cells D11 and D19, respectively, we enter the following formulas:

$$
\begin{aligned}
& (\mathrm{D} 5-2 * \mathrm{D} 10+\mathrm{D} 18) /(3 * \mathrm{D} 6) \\
& (\mathrm{D} 5-2 * \mathrm{D} 18+\mathrm{D} 10) /(3 * \mathrm{D} 6)
\end{aligned}
$$

These are just the solutions derived in Section 2 expressed in terms of the appropriate cells. From there on, the remaining entries are straightforward: 


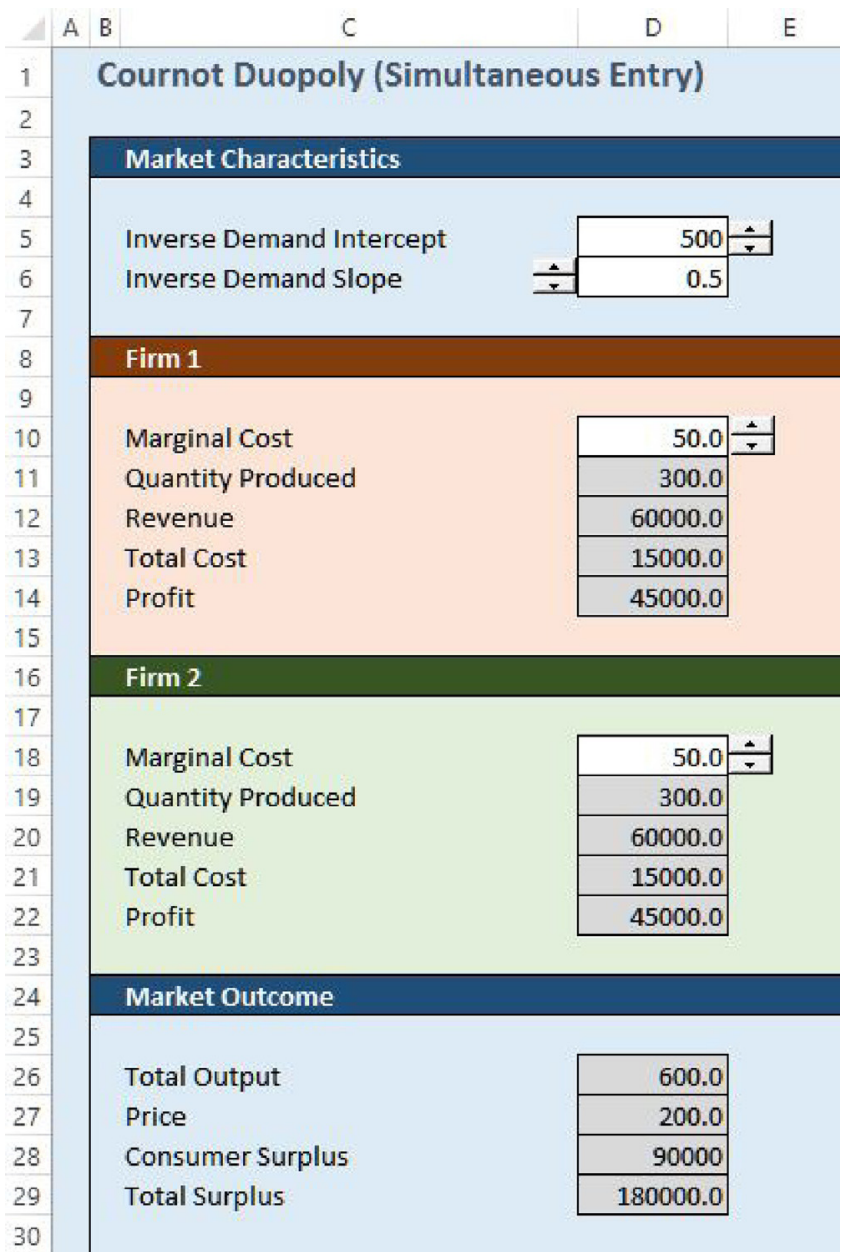

Fig. 3. Excel layout.

- Total output in cell D26 is D11+D19.

- Price in cell D27 is D5 - D6* D26.

- Revenue for firms 1 and 2 in cells D12 and D20 are D11*D27 and D19*D27, respectively.

- Total costs for firms 1 and 2 in cells D13 and D21 are D11*D10 and D19*D18, respectively.

- Profits for firms 1 and 2 in cells D14 and D22 are D12 - D13 and D20 - D21, respectively.

- Consumer surplus in cell D28 is defined as (D5 - D27)*D26/2.

- Total surplus in cell D29 is defined as D14+D22+D28.

Note that it is not necessary to obtain closed form solutions for all of the endogenous variables. We can express the solutions either in terms of exogenous factors directly, or in terms of endogenous factors which have already been expressed in closed form. In effect, Excel will do the necessary substitutions for us.

To complement the numerical solutions, we present graphs, as shown in Fig. 4. The two stacked graphs on the left of the figure present the residual demands faced by each firm, while on the right we have the best response functions. These depictions are much the same as those shown in Section 3 and 
Firm 1

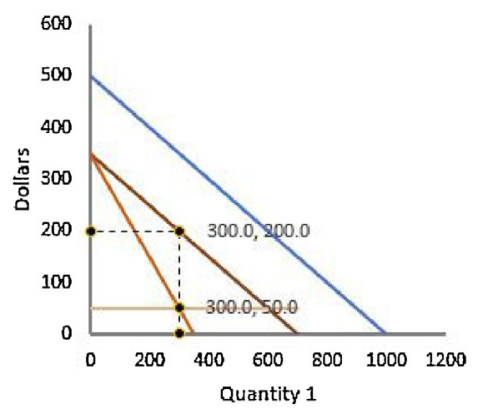

Firm 2

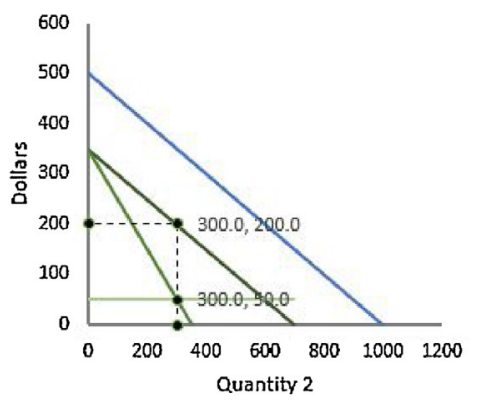

Best Responses

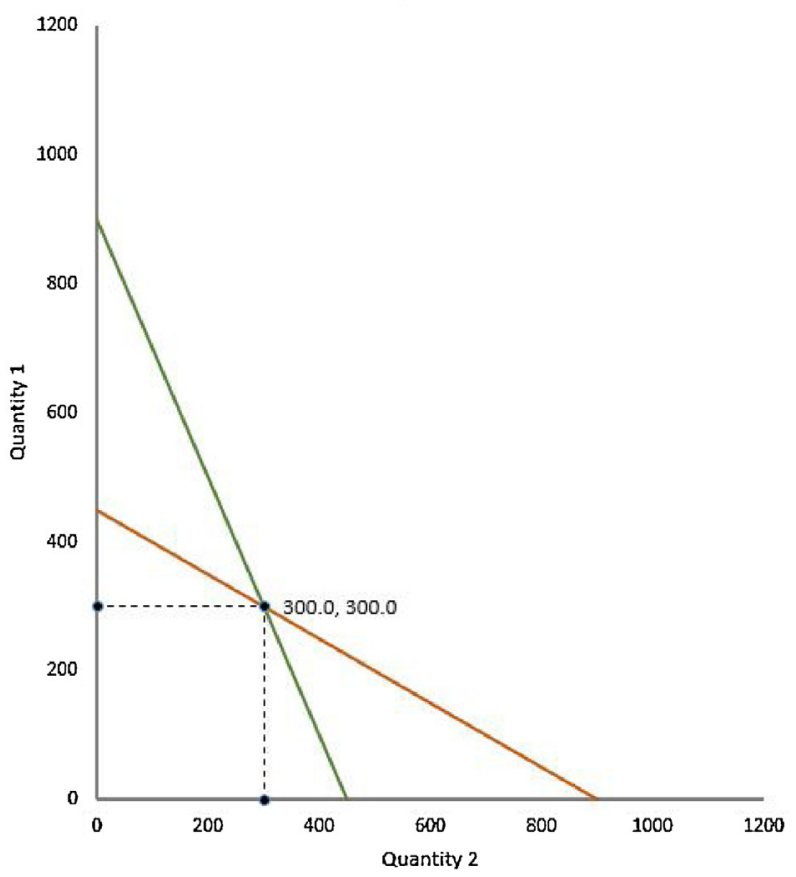

Fig. 4. Excel graphs.

are typical of textbook treatments. However, they are also 'live' and will move directly as the parameters of the model are changed. ${ }^{7}$

We finish the model by adding 'spinners' to allow the parameters of the model to be varied easily and smoothly (and also to prevent entry of parameters values outside the sensible range). ${ }^{8}$ Color coding then provides a mechanism to link the geometry and the tabular results, and to maintain a consistent look and feel across the models.

\section{Obtaining and using the Excel models}

To make the Excel resources as accessible as possible we have set up a webpage where the Cournot model, and a number of extensions described below, can be downloaded. The URL for the website is: http://sites.google.com/site/economicmodelsinexcel/io. To get started, simply download the mod$\mathrm{el}(\mathrm{s})$, open the file(s) in Excel, and try changing any value in a white cell. ${ }^{9}$ The model's numerical solutions and the corresponding graphs should respond instantaneously.

\footnotetext{
${ }^{7}$ The graphs themselves are just connected scatterplots. The data underlying them, which is based on the visible cells, is hidden in the sheet to the right of the model.

${ }^{8}$ There are several alternatives for dealing with the possibility of entering parameter values outside of the range that guarantees an interior solution. One way is to control the possible parameters using the range controls on spinners (possibly in combination with locking the cell content to avoid overwriting). Another is to use conditional statements in the solution cells themselves. For example, if the marginal cost exceeds the price intercept of the residual demand curve, quantity supplied is zero, and is determined by the marginal revenue equals marginal cost condition otherwise. A third approach is simply to do nothing - the solution will cease to make economic sense, and this can be used to lead discussion as to why. If the marginal cost exceeds the intercept of the residual demand, for example, the calculated quantity will be negative. This is of course nonsense, but the reasoning is useful for understanding the model, and is an important lesson in itself. If the marginal cost of production exceeds the highest price any customer would be willing to pay, it cannot make economic sense to produce.

${ }^{9}$ The models were built using the latest version of Excel for Windows, but will work in any recent version of Excel, including Excel for Mac. For users of open-source software, the models will also work in OpenOffice on Windows and Linux platforms. The numerical component of the models even works in web-based platforms, such as Google Docs. However, the graphical capabilities of the latter are not yet sufficient to accommodate the live figures.
} 
We have found this type of model to be pedagogically useful in two distinct ways. First, the models can be used as part of classroom demonstrations, with appropriate projection equipment. The diagrams are much the same as those used in typical textbooks and slides, but have the distinct advantage of being based on a specific numerical example, which many students find helpful, and of responding 'live' to changes in the underlying parameters. Hence it is possible to explore many more scenarios quickly with these types of tools than would be feasible doing numerical examples by hand.

The second way that we have found this type of model useful is as part of guided assignments. In this respect the approach is quasi-experimental. Since the models are deterministic, they are obviously not truly experimental, but assignments can be set up so that students can discover and take ownership of the properties of the model themselves by experimenting with the parameters and observing the resulting changes. Considering the limiting values of parameters is a particularly useful way of developing an understanding of how the models work. Some possible starting points for the Cournot model might be (with learning objectives in italics):

1. Allow the marginal costs to differ across firms. How does the equilibrium output of the low-cost firm compare to the output of the high-cost firm? Which firm has higher profits? We find that the lower cost firm will produce more and make higher profits in equilibrium than the higher cost firm.

2. How does the profit of the two firms depend on the slope of the market demand curve? Can you explain the pattern you observe? The slope of the demand curve relates to the elasticity of demand, which in turn is a measure of the firm's collective market power. The flatter the curve, the less the market power, and consequently the lower the price and profit.

3. Could the cost of one firm be so high that it would choose to produce nothing? If so, how high would the cost have to be? How much would the other firm produce in this case? How would their profit compare to the case where both firms produced? If the cost of one firm is high enough (equal to the price intercept of the residual demand at their rival's optimal output) they will cease to produce. The other firm will respond by fully exploiting its monopoly power and will have greater profit.

4. Imagine that one firm received a subsidy, which lowers its marginal cost, potentially below zero. Is it possible to lower marginal cost so much that the rival chooses to exit the market? It is possible, if the subsidy is enough to drive the market price down to the marginal cost of the rival. In this case the price is at the competitive outcome.

5. Do consumers win or lose in the above scenarios? Consumer surplus depends on the market price, so they lose in scenario 3 and gain in scenario 4.

\section{Extensions}

Following the approach outlined above for the Cournot duopoly case, we built several variations to allow students to see how different market structures affect the equilibrium outcome and how these market structures relate. With each variation, we solve the model and enter it into Excel exactly as outlined above for the Cournot case, taking care to maintain consistency in presentation across the models. Because of the similarity in the basic approach, we omit a detailed discussion and focus on a brief description of the model extensions and the exercises that can help students learn key features of the extensions and how the models relate to one another.

\subsection{Differentiated goods}

The basic Cournot model assumes that the firms produce a homogeneous good. Many industries, however, are comprised of firms producing similar but not identical products. These products are often distinguished by different branding. Examples include different varieties of cereal, different types of fast food restaurants, or different models of cars. To capture the nature of interactions between firms with related products, the differentiated goods model extends the simple Cournot duopoly case by modifying the market demand structure. The model allows firms to face related but 
different inverse demand curves, while retaining the assumption of simultaneous quantity choices. The inverse linear demands are given as follows: ${ }^{10}$

$$
\begin{aligned}
& p_{1}\left(q_{1}, q_{2}\right)=\alpha_{1}-\beta_{1} q_{1}-\beta_{2} q_{2} \\
& p_{2}\left(q_{1}, q_{2}\right)=\alpha_{2}-\beta_{2} q_{1}-\beta_{1} q_{2}
\end{aligned}
$$

Here, $\beta_{1}^{2} \geq \beta_{2}^{2}$ so that the price of a good responds more to a change in the quantity of that good than to a change in the quantity of the related good. The $\beta_{2}$ parameter captures how closely related the two products are. If the products are not at all closely related, then $\beta_{2}$ approaches 0 . At the other extreme, if products are homogenous, then $\beta_{2}=\beta_{1}$.

The solution procedure is essentially the same as that set out in Section 2 . The model is useful for showing how product differentiation relates to market power. If the products of both firms are very similar, the model gives results approaching Cournot. If the products of the two firms are unrelated, then each firm will act as a monopoly. Some exercises that can be conducted to illustrate these concepts include:

1. Give examples of products where the slope parameter on the rival good $\left(\beta_{2}\right)$ approaches zero. Give examples of products where the slope parameter on the rival good $\left(\beta_{2}\right)$ approaches the demand slope $\left(\beta_{1}\right)$. When the $\beta_{2}$ parameters are zero, the goods are unrelated. Examples are numerous and may include butter and footballs, staplers and tennis shoes, etc. When $\beta_{1}$ approaches $\beta_{2}$, goods are very close substitutes. Examples are numerous and may include yellow pencils and blue pencils, white bread and wheat bread, etc.

2. What happens to the prices, quantities, and profits of each firm as the slope parameter on the rival good approaches zero? When the $\beta_{2}$ parameters are zero and the goods are unrelated, we have two monopolists.

3. What happens to the slope of the best response function of each firm when the rival slope decreases? Explain why the slope of the response function changes. It becomes steeper/flatter. This is telling us that the firm's do not respond to one another.

4. Set the demand rival slope equal to the demand slope. Compare your results to the Cournot duopoly model with the same demand slope and costs. Do you get the outcome you expected? When $\beta_{1}=\beta_{2}$ and the goods are perfect substitutes, i.e., homogeneous, the model coincides with the standard Cournot model.

\subsection{Many firms}

The many firm case mirrors the Cournot duopoly case, but allows the user to choose the number of firms in the market, $n$, where $n \geq 1$. We have set the problem up such that firm 1 may have a cost structure that differs from all the other firms, in order to maintain consistency with the other Excel sheets. Since all firms enter simultaneously, the problem is not substantially different than the one discussed in Section 2. This sheet is particularly useful for considering the relationship between Cournot, monopoly and competitive market outcomes, the key result being that the Cournot model converges to the competitive outcome.

Geometrically, the equilibrium can be illustrated by modifying the best response diagram. Fig. 5 is drawn in the space of the output choice for firm 1, and the aggregate output of the remaining firms (we can aggregate by virtue of homogeneity). Suppose that there are three firms. The best response $R_{1}$ shows the profit maximizing level of output for firm 1 given any level of aggregate output by the other two firms, and is the same as before (since the firms are identical, firm 1 is indifferent as to the source of rival production.)

The curve labeled $n R_{2}$ represents the aggregate best responses of the two rivals. Should firm 1 produce at the competitive output level, the optimal response of all rivals is to produce nothing. Hence, the horizontal intercept of the aggregate best response is the same as for an individual rival firm. If firm 1 produces nothing, however, the remaining two firms will operate as a duopoly,

\footnotetext{
${ }^{10}$ See Dixit (1979) and Singh and Vivies (1984) for the derivation of this demand system from a utility framework.
} 


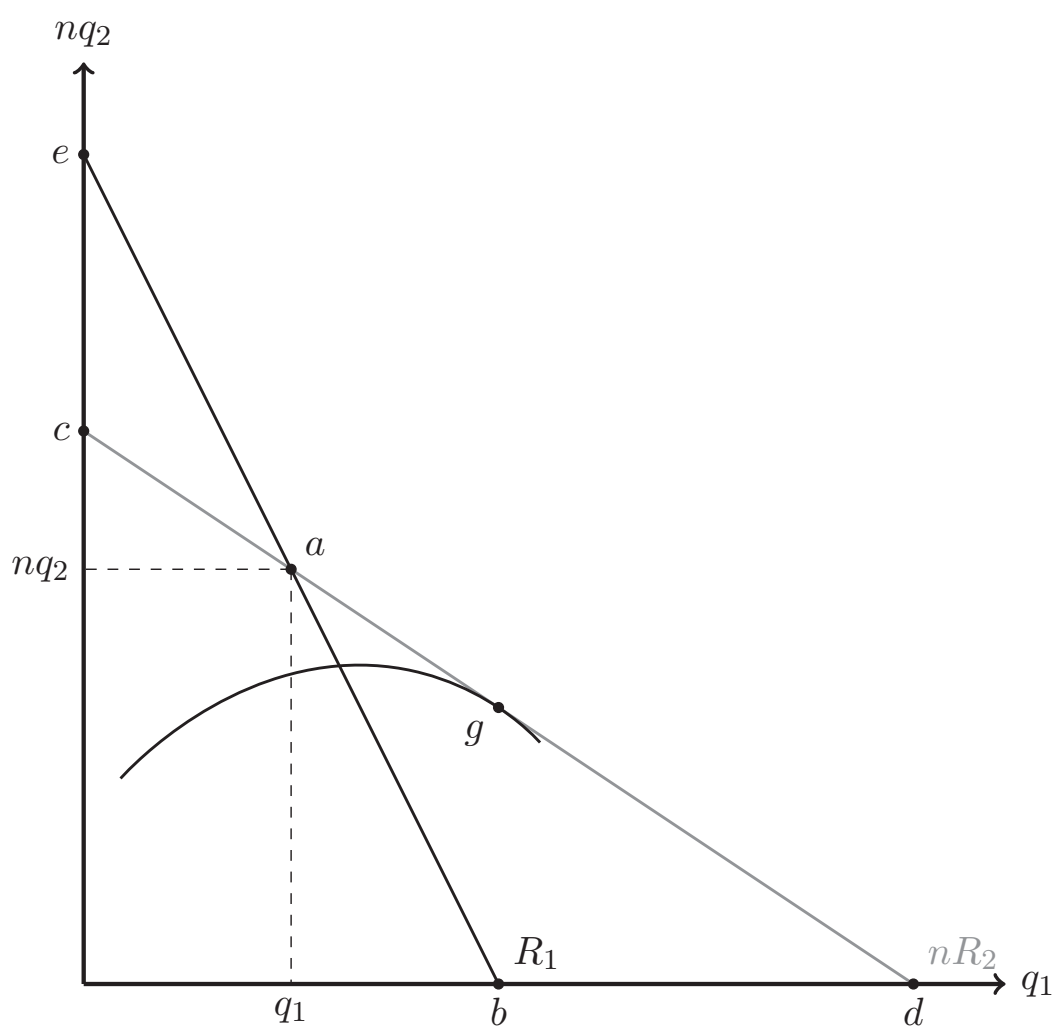

Fig. 5. Equilibrium outcomes with more than two firms.

producing a higher level of output than a monopoly (since the Cournot output level exceeds the joint profit maximizing, or monopoly, output level). Hence the vertical intercept of the aggregate best response function is higher than for a single firm. ${ }^{11}$ The Cournot outcome is at the intersection of the best response functions (point $a$ ). Total market output at the Cournot equilibrium must be higher with three firms than with two (and higher still with four, and so on) even though each firm produces less (since the best response functions slope downward.) Some useful exercises that can be conducted with this simulation model include the following:

1. If you set number of other firms equal to zero, how does the outcome compare to that of a monopoly? With only one firm, the outcome will be monopoly. Cournot oligopoly converges to monopoly as the number of firms approaches 1 .

2. If you set number of other firms equal to one, how does the outcome compare to the Cournot duopoly with the same demand and cost parameters? This case will simply replicate the Cournot duopoly.

3. What happens to the total output, price, and total surplus as the number of firms increases? As the number of firms increases, output rises, price falls and total surplus rises. The price should get closer and closer to marginal cost. The Cournot model converges to the competitive outcome.

\footnotetext{
${ }^{11}$ In fact, for the symmetric case with linear demands and constant marginal costs, Cournot output is 33.3 percent higher than the monopoly output, as can be easily verified in the simulation models.
} 


\subsection{Stackelberg duopoly}

The Stackelberg duopoly returns to the homogenous good case and two firm assumptions of the Cournot duopoly. The model differs from Cournot by allowing firms to act sequentially instead of simultaneously. Firm 1 is the leader and chooses its quantity first while firm 2 is the follower and chooses its quantity after observing firm 1's choice. This is a classic model for depicting first-mover advantage.

The game is solved via backward induction. Firm 2 will solve the same problem as in the Cournot case, which will yield the same best response function. Firm 1 can predict firm 2's best response function and will take this into account when choosing how much quantity to produce in the first period. Mathematically, firm 1 maximizes its profit subject to the market conditions, its own cost, and firm 2's output, assuming that firm 2 will maximize its own profit in response to firm 1's choice. ${ }^{12}$ Some useful exercises with this model include:

1. Compare the total equilibrium output and price obtained in the Stackelberg Model to the Cournot Model (keeping costs and demand parameters constant). Why do the results differ? The total output is actually higher in Stackelberg than in Cournot, and the price correspondingly lower.

2. Set costs of firm 1 equal to the costs of firm 2. Compare the first mover's (firm 1) production and profit to second mover's production and profit. Who is better off? How do the results compare to the Cournot duopoly? Firm 1 produces more output and attains a higher profit - there is a first-mover advantage in this model.

3. In the Cournot duopoly model, suppose that firm 1 received a subsidy from the government that reduced its marginal cost, possibly below zero. Is it possible for a subsidy to generate the Stackelberg output levels? How much profit would firm 1 make if so? How much would they make net of the subsidy payments? This exercise reveals the logic underlying strategic trade policy (if we imagine the firms being in separate countries). A subsidy that induces firm 1 to produce the Stackelberg output level induces firm 2 to reduce its output similarly. The subsidy is equivalent to granting a firstmover advantage, and profit net of subsidy payments is maximized.

\subsection{Stackelberg with many firms}

Next we combine the Stackelberg model with the many firms model. In this case, firm 1 moves first, and then all the other firms choose quantity simultaneously in the follower round after observing firm 1 's choice. Again, the model is solved via backwards induction.

The equilibrium outcome can be seen in Fig. 5, at point $g$. As noted above, this diagram is drawn in the space of the output choice for firm 1, and the aggregate output of the follower firms. Once again, the key point is that the aggregated best response function for the rival firms rotates upward around the horizontal intercept when the number of rival firms increases. This increases the total market output and lowers the price. With a large number of firms in the second stage, we effectively have a short-run variant of the dominant firm with a competitive fringe model.

1. What happens to the profits of the first mover as the number of second movers increases? It declines. This is the key result from this model, the first mover advantage diminishes when the number of rivals is large (and disappears when the second stage is competitive.)

2. Is there some point where the number of rival firms would not rise further? If we imagine that firms can choose to be in the second stage or not then yes, eventually the price would fall below the marginal cost of the second mover firms, and entry would not make sense. We explore this idea further with the next model.

3. What happens to the output of the first mover as the number of second movers increases? It remains constant. The lesson is that being a first mover can lead to dominant market share, even if it doesn't always lead to a profit advantage.

\footnotetext{
12 The outcome is depicted in Fig. 2 as point $g$, the best isoprofit of firm 1 that can be reached while staying on firm 2's best response.
} 
4. Assume that the number of firms in the second stage must be such that profit for the typical second mover is just above zero. If the marginal cost of the first mover falls, what must happen to the number of second movers? If the marginal cost of the first mover is lower, it can profitably produce more. For given demand conditions, this leaves less market share for the second movers. Hence, their number must decline unless they (temporarily) accept losses.

\subsection{Monopolistic competition}

In our final extension, we show how we can use the basic Cournot setup to derive a model of monopolistic competition. We return to a simultaneous move game with many firms, but the number of firms is no longer fixed. Instead, firms face both marginal and fixed costs and the number of firms that exist in the market is determined endogenously. The number of firms is decided by an entry condition, with firms entering until zero profit holds. Again for consistency across the models, we allow firm 1 to have (potentially) different costs than the remaining firms. ${ }^{13}$

1. What is the profit of firm 1 if costs are the same as all other firms? All firms make zero profit in equilibrium in this case.

2. How does the profit of firm 1 change if the marginal cost falls? If the fixed cost falls? If firm 1 has lower costs (marginal or fixed) it will make higher profits, although only the marginal costs affect output.

3. What happens to the number of firms as fixed costs increase? The number of firms falls, some must exit in order to keep price at average cost.

4. How many firms do you think would enter if the fixed cost of production was equal to the profit firm's made in the Cournot duopoly (assuming symmetry)? The optimal number of firms would be two. The market outcome would replicate Cournot, with the exception of producer profits.

4. What would happen if fixed costs were very close to zero? The market outcome would replicate perfect competition. This can be verified by comparing to the Cournot model with many firms.

\section{Concluding comments}

Numerical simulation is a very useful tool for reinforcing students' economic intuition on model behavior and for emphasizing the linkages between various economic models. The common foundation of the models can sometimes be lost when covering many seemingly different structures. Hence, much can be learned by experimenting with model parameters and seeing how the results of different models converge, and numerical simulation models are well-suited to this task. Industrial organization, with its almost limitless variety of models of market structure, is a particularly useful area of application.

In this paper we have outlined a set of new resources that can be used to aid in teaching basic models of strategic competition in quantities and extensions, along with suggestions for how they can be used. The models are all built in Excel, use a consistent interface, and are freely available for download. We presented a total of six models in this paper. There are of course many other possible variations. We could, for example, set up a model with differentiated goods and many firms or differentiated goods with sequential entry.

The techniques that we have applied in building these models can be easily adapted to related problems, and indeed to practically any economic theory taught at the undergraduate level. For industrial organization in particular, it would be useful to develop similar models of strategic competition in prices. Starting with the differentiated goods model described in this paper, it would be possible to build a model of Bertrand duopoly, and perhaps extend it to a model of price leadership, for example.

\footnotetext{
${ }^{13}$ As it is set up, the costs of firm 1 should be no higher than the costs of the remaining firms. Also note that non-integer firm numbers are allowed.
} 


\section{References}

Briand, G., Hill, R.C., 2013. Teaching basic econometric concepts using Monte Carlo simulations in Excel. Int. Rev. Econ. Educ. 12, 60-79.

Cabral, L., 2000. Introduction to Industrial Organization. The MIT Press, Cambridge and London.

Carlton, D., Perloff, J., 2005. Modern Industrial Organization, 4th ed. Pearson/Addison-Wesley, Boston.

Dixit, A., 1979. A model of Duopoly suggesting a theory of entry barriers. Bell J. Econ. 10, 20-32.

Durlauf, S., Blume, L., 2008. The New Palgrave Dictionary of Economics, 2nd ed. Palgrave Macmillan, Basingstoke and New York.

Findley, T.S., 2014. Using MS Excel to solve and simulate the LC/PI model of consumption and saving. Int. Rev. Econ. Educ., forthcoming.

Gilbert, J., Oladi, R., 2011. Excel models for international trade theory and policy. J. Econ. Educ. 42 (1), 95.

Guo, N., Gilbert, J., 2014. Demystifying financial markets for saving and insurance with numerical models. J. Econ. Educ. 45 (1), 78.

Mixon, J.W., Tohamy, S., 2000. Using Microsoft Excel in principles of economics. Comput. High. Educ. Rev. 14 (2) .

Singh, N., Vivies, X., 1984. Price and quantity competition in a differentiated Duopoly. Rand J. Econ. 15, 546-554.

Wight, J.B., 1999. Using electronic data tools in writing assignments. J. Econ. Educ. 30, 21-27. 